\title{
TREATMENT POSSIBILITY FOR AAA OF THE VISCERAL BRANCHES REGION
}

\author{
Petr Utíkal ${ }^{\mathrm{a}}$, Martin Köcher ${ }^{\mathrm{b}}$, Jiřina Koutnác, Petr Bachleda ${ }^{\mathrm{a}}$, Petr Dráč ${ }^{\mathrm{a}}$, Marie Černáb, \\ Eva Buriánkováb ${ }^{\text {, Jiří Herman }}{ }^{a}$
}

\author{
a $2^{\text {nd }}$ Clinic of Surgery, Teaching Hospital, Olomouc, Czech Republic \\ e-mail petr.utikal@fnol.cz \\ ${ }^{b}$ Clinic of Radiology, Teaching Hospital, Olomouc \\ c Clinic of Anestesiology, Teaching Hospital, Olomouc
}

Received: May 12, 2005; Accepted: June 21, 2005

Key words: Aorta/Aneurysms/Morphology/Repair/Endovascular/Stent-graft/Visceral branches/Revascularisation/Combined strategy

The authors describe a promising abdominal aortic aneurysm treatment - a combined endovascular/surgical approach - used in two cases of aneurysm taking the aortic visceral branches region.

\section{INTRODUCTION}

Fatal prognosis and unsatisfactory urgent surgery results lead to the tendency for elective treatment of all abdominal aortic aneurysms (AAA) ${ }^{1-3}$. Today, we have two basic possibilities of repairing AAA - conventional open surgery (OS) and endovascular stent-grafting (EVAR) ${ }^{4-6}$. Unfortunately, both methods have their limitations. The indication for EVAR is determined by the AAA morphology, OS is limited by the patient's individual operating risk $^{3,7-12}$. First of all, we have to respect the fact that the risk of AAA repair always has to be lower than the risk of AAA rupture ${ }^{13}$. For this reason any morphologically complicated AAAs are problematic to treat, especially in high risk patients. One posssibility exists. We can take the positives and advantages of both methods and eliminate their disadvantages combining the endovascular and surgical procedures ${ }^{14-16}$.

\section{PATIENTS}

Both AAA patients had good life expectancy, but they were a high risk for open aortic surgery (ASA III-IV) with AAA taking the entire visceral branches region. Considering the high operating risk and the AAA's complicated morphology, which were problematic for conventional AAA repair, the patients were observed (6 and 12 months) first. However the AAAs of large diameter (5.5 and $6 \mathrm{~cm}$ ) rapidly increased ( 5 and $8 \mathrm{~mm}$ over the last 6 months) with indefinite but new symptoms in back. The treatment indication became acute. We had to decide in favour of repair and we chose the combined endovascular/surgical approach.

\section{Patient No 1.}

A man of 61, with AAA of the aortic visceral branches region. There was one anatomical anomaly - the hepatic artery arising from the superior mesenteric artery (Fig. 1 A, B). It was an advantage in this case and saved us one bypass. The first part of the AAA repair was the bypasses creation. The visceral aneurysmal sac branches (their peripheral parts) and common iliac arteries exposure was the first step. Then we began the iliac-superior mesenteric bypass inflow anastomosis created with the prosthesis end to the side of the common iliac artery on the right side. The outflow anastomosis was created with the prosthesis end to the superior mesenteric artery side. The right renal artery was joined with a short prosthesis interposition. The left kidney was revascularised by iliacrenal bypass on the left side created in this manner. In order to prevent retrograde flow to the aneurysmal sac we closed the central parts of revascularised visceral branches by ligation. Coeliac trunk closure was possible without its revascularisation. The hepatic artery, being the most important branch, arose from the superior mesenteric artery. The spleen was removed and for the stomach there was enough colateral circulation from the superior mesentric artery region. The second part of the AAA repair was the stentgraft implantation and the first step was creating a temporary access using dacron prosthesis anastomosed with the aorta (Fig. 1C). We used the aortic tube type of stentgraft. In order to achieve a better stentgraft fixation and prevent perigraft leak we added distal aortic banding using a strip of dacron prosthesis (Fig. 1 D).

\section{Patient No 2.}

A man of 55, with AAA of the entire abdominal aorta, with atherosclerotic occlusion of the common iliac artery on the right side and a severely stenosed common iliac artery on the left side. The procedure sequence and the single steps were identical with the previous case. We had 

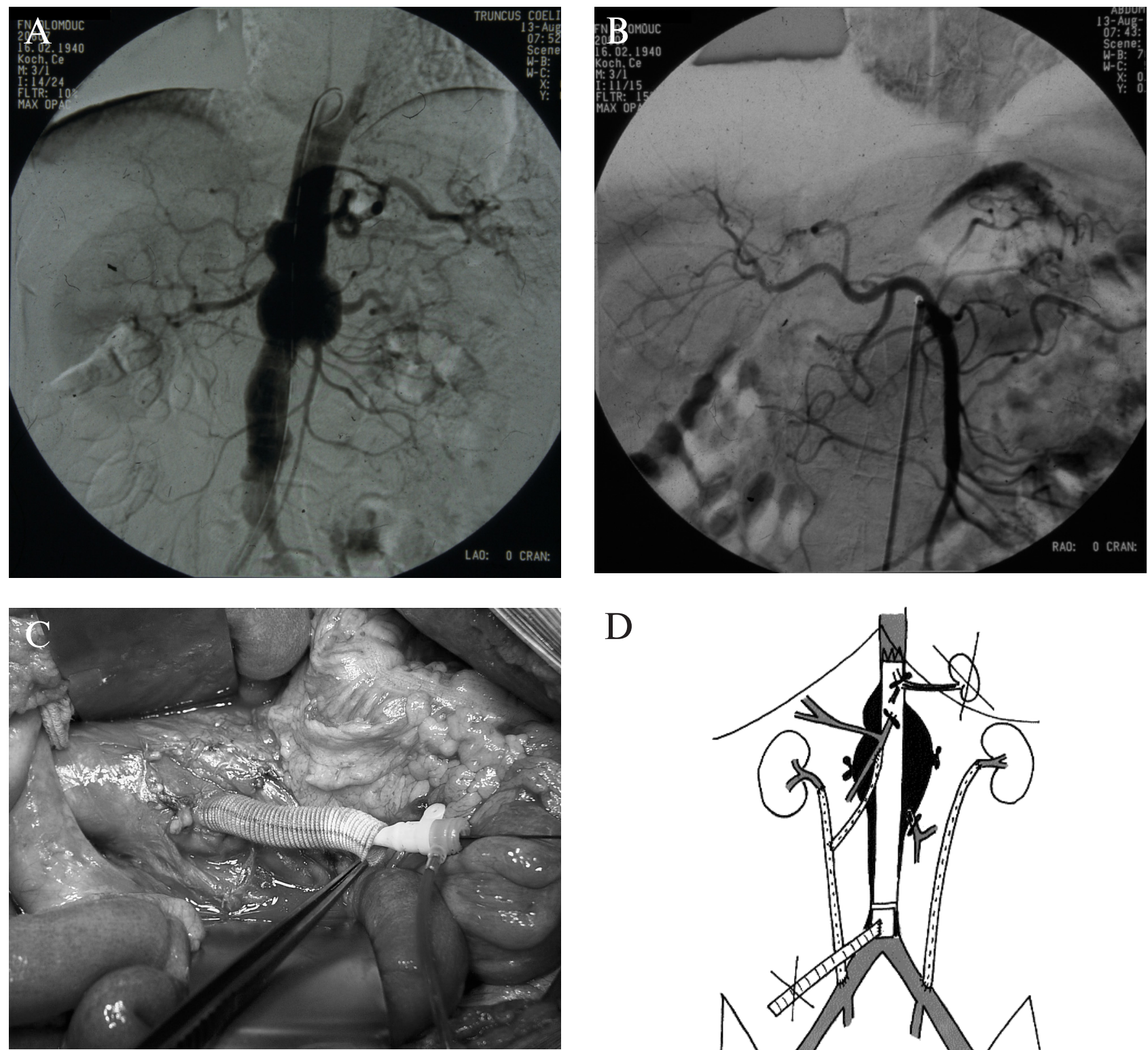

$\mathrm{D}$
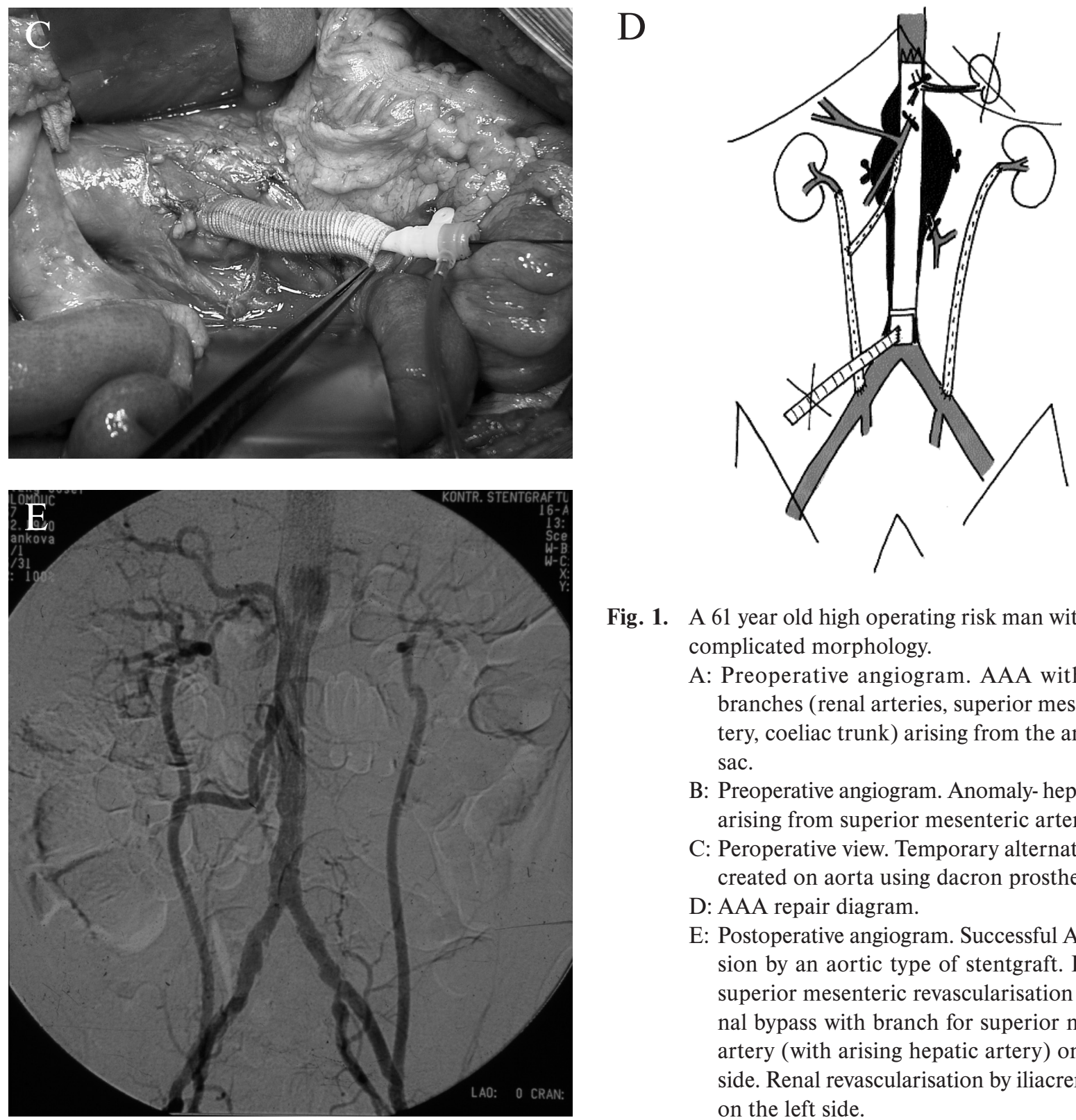

Fig. 1. A 61 year old high operating risk man with AAA of complicated morphology.

A: Preoperative angiogram. AAA with visceral branches (renal arteries, superior mesenteric artery, coeliac trunk) arising from the aneurysmal sac.

B: Preoperative angiogram. Anomaly- hepatic artery arising from superior mesenteric artery.

C: Peroperative view. Temporary alternative access created on aorta using dacron prosthesis.

D: AAA repair diagram.

E: Postoperative angiogram. Successful AAA exclusion by an aortic type of stentgraft. Renal and superior mesenteric revascularisation by iliacrenal bypass with branch for superior mesenteric artery (with arising hepatic artery) on the right side. Renal revascularisation by iliacrenal bypass on the left side. 
A

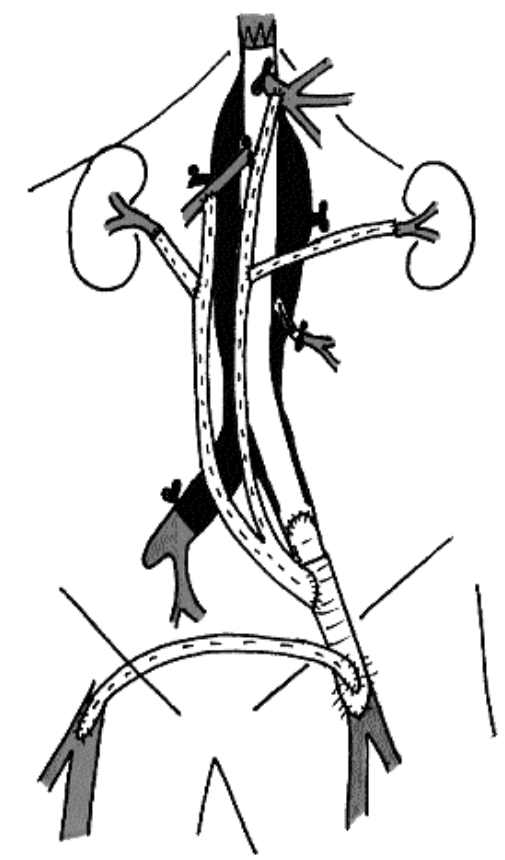

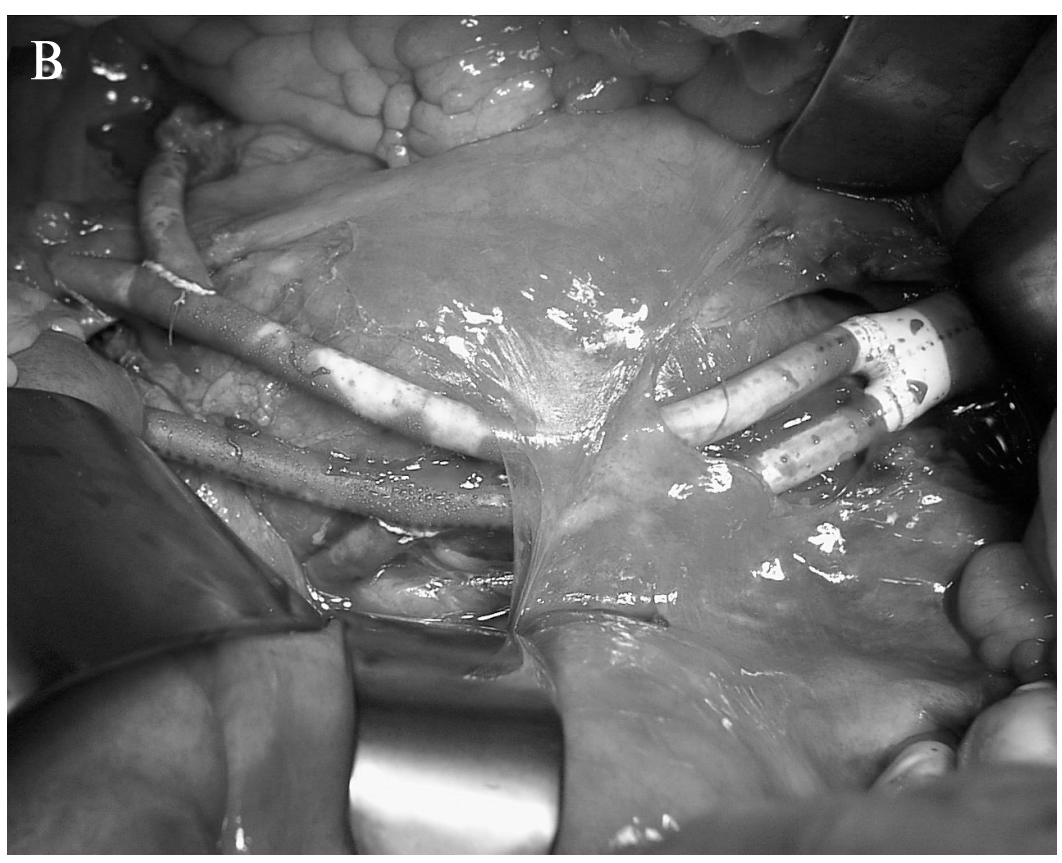

Fig. 2. A 55 year old high operating risk man with AAA of complicated morphology

A: AAA repair diagram.

B: Peroperative view. Reversed bifurcated type of ePTFE prosthesis for superior mesenteric artery and coeliac trunk with branches for renal arteries.

to revascularise all the visceral branches and a reversed bifurcated prosthesis was used as the basis. The inflow anastomosis was created with the end of the prosthesis body to the side of the dacron iliac-iliac interposition on the left side. The right prosthesis limb was anastomosed end to side with the superior mesenteric artery, while the left one was anostomosed with the coeliac trunk. Renal arteries were joined with the limbs using a short prosthesis interposition. The central parts of the visceral branches were closed by ligation and the AAA was excluded by an aortouniiliac stentgraft which was introduced by dacron iliac-iliac interposition. Finally, an iliac-femoral cross over bypass from the left side was created (Fig. 2 A, B).

The procedures were conducted under general anesthesia in the operating theatre and under the usual conditions for vascular surgery (antibiotics, heparinisation), but with special revascularised multiorgan protection and promotion during the entire perioperative period. Transperitoneal operating access to the aorta and the visceral branches was used in both patients.

We used the ELLA stentgraft system (ELLA CS, Hradec Králové, Czech Republic) for AAA exclusion and mostly ePTFE prosthesis for bypass creation. A reversed bifurcated prosthesis (14/7 diameter) seems to be the best basis for a multiple bypass. For an alterative (temporary or permanent) access we used a dacron prosthesis with a diameter corresponding with that of the stentgraft introducing system.
Technical success was achieved in both patients. There were no serious complications in relation to the associated surgery. AAA was primarily successfully excluded, all bypasses are primarily patent, the function of the revascularised organs has been restored and the patients are alive after 2 years (Fig. 1 E).

\section{DISCUSSION AND CONCLUSION}

Endovascular AAA sac exclusion using a stentgraft is hemodynamicaly less stressful as well as miniinvasive ${ }^{15,17-20}$. The associated bypass creations on the visceral branches are more invasive, but they are hemodynamically still less stressful and acceptable in the case of high operating risk patients $^{15,16}$. In this combined type of AAA repair we need no exposure of the aneurysmal proximal neck or the aneurysmal sac with the origins of its branches (their exposure would be technically very problematic in this location) as in classical AAA surgery ${ }^{4}$. The proximal neck anastomosis is created endovascularly and the bypasses outflow anastomoses are created on the free peripheral parts of the visceral branches. The procedure sequence - bypass creation followed by the ligation of the visceral branches central parts and then by AAA exclusion - prevents organ ischaemia and thrombembolic complications during stentgraft introduction. 
The combination of the endovascular and surgical procedures (combined strategy) should generally allow the treatment of morphologically complicated AAAs and the repair should be easy, feasibile and safe, as in the cases reported above ${ }^{15,16}$. If important organ revascularisation after AAA sac with visceral branches endovacular exclusion is required, an associated surgical bypass seems to be the best possibility available ${ }^{16}$. The promising branched graft, which is, in general, clinically used as a separate endovascular repair, is still a question of the future ${ }^{21}$.

Thus, the combined strategy should currently be the method of choice for all patients (not only for the high operating risk ones) with AAA taking the entire aortic visceral branches region.

\section{REFERENCES}

1. Vardulaki KA, Prevost TC, Walker NM, Day NE, Wilmink AB Quick CR. ( 1998) Growth rates and risk of rupture of abdominal aortic aneurysms. Br J Surg 85, 1674-1680.

2. Budd JS, Finch DRA, Carter PG. (1990) A study of the mortality from ruptured abdominal aortic aneurysms in district comunity. Eur J Vasc Surg 11, 1-6.

3. Blankensteijn JD. (2000) Mortality and morbidity rates after conventional abdominal aortic aneurysm repair. Semin Intervent Cardiol 5, 7-13

4. Dubost C, Allary M, Oeconomos N. (1952) Resection of an aneurysm of the abdominal aorta. Arch Surg 64, 405-408

5. Parodi JC, Palmaz JC, Barone HD. (1991) Transfemoral intraluminal graft implantation for abdominal aortic aneurysms. Ann Vas Surg 5, 4912-499.

6. Parodi JC, Ferreira M. (2000) Why endovascular abdominal aortic aneurysm repair? Semin Intervent Cardiol 5, 3-6.

7. Schumacher H, Allenberg JR, Eckstein HH. (1996) Morphological classification of abdominal aortic aneurysm in selection of patients for endovascular grafting. Br J Surg 83, 949-950.

8. Carpenter JP, Baum RA, Barker CF. (2001) Impact of exclusion criteria on patient selection for endovascular abdominal aortic aneurysm repair. J Vasc Surg 34, 1050-1054.

9. Schumacher H, Eckstein HH, Kallinowski F. (1997) Morphometry and classification in abdominal aortic aneurysms: patient selection for endovascular and open surgery. J Endovasc Surg 4, 39-44.
10. Teufelsbauer H, Prusa AM, Wolff K, Polterauer P, Nanobashvili J, Prager M, Holzenbein T, Thurnher S, Lammer J, Schemper M, Kretschmer G, Huk I. (2002) Endovascular stent-grafting versus open surgical operation in patients with infrarenal aortic aeurysms. A propensity score-adjusted analysis. Circulation 106, 782-787.

11. Teufelsbauer H, Prusa AM, Wolff K, Sahal M, Polterauer P, Lammer J, Holzenbein T, Kretschmer G, Huk I. (2003) The impact of endovascular stent-grafting on reducing mortality rates after surgical treatment of abdominal aortic aneurysms. Eur J Vasc Endovas Surg 26, 494-500.

12. May J, White GH, Yu W, Ly CN, Waugh R, Stephen MS. (1998) Concurent comparison of endoluminal versus open repair in the treatment of abdominal aortic aneurysms' analysis of 303 patients by life-table method. J Vasc Surg 27, 213-221.

13. Mohan IV, Harris PL. (2000) When not to operate for abdominal aortic aneurysms. Semin Intervent Cardiol 5, 15-19.

14. Utíkal P, Köcher M, Bachleda P, Dráč P, Buriánková E, Kojecký Z, Ürge J. (2001) Léčba AAA na přelomu tisíciletí - stentgrafting - role cévního chirurga. Prakt Flebol 10, 111-113.

15. Utíkal P, Köcher M, Koutná J, Bachleda P, Dráč P, Černá M, Buriánková E. (2004) AAA elective treatment indication tactics in EVAR era. Biomed Pap Med Fac Univ Palacky Olomouc 148, 183-187.

16. Utíkal P, Köcher M, Bachleda P, Dráč $\mathrm{P}$, Černá M, Buriánková E.(2004) Iliac-renal bypass in EVAR of AAA with renal arteries arissing from aneurysmal sac. Biomed Pap Med Fac Univ Palacky Olomouc 148, 179-182.

17. Becquemin JP, Bourriez A, D’Audiffret A, Zubilewitz T, Kobeiter H, Allaire E, Melliére D, Desgranges P.(2000) Mid-term results of endovascular versus open repair for abdominal aortic aneurysms in patients anatomically suitable for endovascular repair. Eur $\mathbf{J}$ Endovasc Surg 19, 656-661.

18. Utíkal P, Köcher M, Bachleda P, Novotný J, Ürge J, Dráč P. (2000) Tř́leté zkušenosti se stentgraftingem AAA ve FN UP v Olomouci. Prakt flebol 9, 175-179.

19. Köcher M, Utíkal P, Buriánková E, Koutná J, Bachleda P, Novotný J, Heřman M, Benýšek V, Bučil J, Černá M. (2001) Čtyřleté zkušenosti se stentgraftem Ella v endovaskulární léčbě AAA. Čes Radiol $55,159-166$.

20. Köcher M, Utíkal P, , Koutná J, Bachleda P, Buriánková E, Heřman M, Bučil J, Benýšek V, Černá M, Kojecký Z. (2004) Endovascular treatment of abdominal aortic aneurysms-6years of experience with Ella stent-graft system. Eur J of Radiol 51, 181-188.

21. Vos AWF, Linsen MAM, Wisselink W, Rauwerda JA. (2004) Endovascular grafting of complex aortic aneurysms with a modular side branch stent-graft system in a porcine model. Eur J Vasc Endovasc Surg 27, 492-497. 